\title{
Phylogenetics and biogeography of a spectacular Old World radiation of butterflies: the subtribe Mycalesina (Lepidoptera: Nymphalidae: Satyrini)
}

\author{
Ullasa Kodandaramaiah ${ }^{1 *}$, David C Lees ${ }^{2,3}$, Chris J Müller ${ }^{4}$, Elizabeth Torres ${ }^{5}$, K Praveen Karanth $^{6}$, Niklas Wahlberg ${ }^{1,7}$
}

\begin{abstract}
Background: Butterflies of the subtribe Mycalesina (Nymphalidae: Satyrinae) are important model organisms in ecology and evolution. This group has radiated spectacularly in the Old World tropics and presents an exciting opportunity to better understand processes of invertebrate rapid radiations. However, the generic-level taxonomy of the subtribe has been in a constant state of flux, and relationships among genera are unknown. There are six currently recognized genera in the group. Mycalesis, Lohora and Nirvanopsis are found in the Oriental region, the first of which is the most speciose genus among mycalesines, and extends into the Australasian region. Hallelesis and Bicyclus are found in mainland Africa, while Heteropsis is primarily Madagascan, with a few species in Africa. We infer the phylogeny of the group with data from three genes (total of $3139 \mathrm{bp}$ ) and use these data to reconstruct events in the biogeographic history of the group.

Results: The results indicate that the group Mycalesina radiated rapidly around the Oligocene-Miocene boundary. Basal relationships are unresolved, but we recover six well-supported clades. Some species of Mycalesis are nested within a primarily Madagascan clade of Heteropsis, while Nirvanopsis is nested within Lohora. The phylogeny suggests that the group had its origin either in Asia or Africa, and diversified through dispersals between the two regions, during the late Oligocene and early Miocene. The current dataset tentatively suggests that the Madagascan fauna comprises two independent radiations. The Australasian radiation shares a common ancestor derived from Asia. We discuss factors that are likely to have played a key role in the diversification of the group.

Conclusions: We propose a significantly revised classification scheme for Mycalesina. We conclude that the group originated and radiated from an ancestor that was found either in Asia or Africa, with dispersals between the two regions and to Australasia. Our phylogeny paves the way for further comparative studies on this group that will help us understand the processes underlying diversification in rapid radiations of invertebrates.
\end{abstract}

\section{Background}

Knowledge of phylogenetic relationships among the species comprising a rapid radiation has proved invaluable for detailed investigations into the processes and patterns of their diversification. There are still relatively few studies aimed at understanding the mechanisms of radiations for invertebrates, even in popular groups such as butterflies which feature prominent model-organisms in evolutionary biology [1]. It is the lack of robust phylogenies for such groups that has imposed a crucial impediment for comparative analyses. Among butterflies, a

\footnotetext{
* Correspondence: ullasa.kodandaramaiah@zoologi.su.se

'Department of Zoology, Stockholm University, 10691 Stockholm, Sweden
}

phylogenetic perspective has been applied to a number of radiations (e.g. [2-6]). However, few butterfly groups can compare with the mycalesine radiation (Nymphalidae: Satyrinae: Satyrini: Mycalesina) in terms of diversity of species and geographic sweep. They have been acclaimed as one of the most spectacular butterfly radiations, comprising more than 270 species usually placed in six genera $[7,8]$. Mycalesines are found across the Old World tropics in both forested and open habitats and are characterized by high levels of endemicity throughout their range. Unlike other butterfly radiations, which typically peak in diversity within a single zoogeographic region (e.g. Arhopala in SE Asia), all major palaeotropical regions - Madagascar, Africa, the Indian subcontinent, 
Indo-China, the larger islands of South-East Asia (notably Sulawesi), New Guinea and the Solomon Islands are each represented by a species-rich mycalesine fauna. The Indo-Australian, Afrotropical and Madagascan regions have roughly equal numbers of species [7]. This group of butterflies thus presents an exciting opportunity to understand their diversification within a phylogenetic framework.

The level of diversity in fundamental body plan and in larval and adult feeding biology is relatively modest compared to other butterfly groups with similar species richness. This relative morphological and behavioural conservatism contrasts sharply with a spectacular array of scent organs found in males and some striking differences in expression of wing ocelli and colour patterns $[7,9]$. The existing generic classification scheme has been based mostly on limited morphological characters such as the presence of hairy eyes (interommatidial setae), forewing venation [9-11] or scent organs [12], which have been considered inadequate character sets for resolving their systematics [13-15]. The circumscriptions of genera have been in a constant state of flux, with early revisions for instance [12] and [16] for Asian and African species respectively, and several more recent local revisions based on morphology.

Despite work on regional mycalesine faunas, there has been no coherent attempt to date to classify the entire group. The need for robust phylogenetic hypotheses from molecular data to resolve this issue has been stressed [8,17]. A study on the mycalesines of Madagascar (also including a few African species; [8]) using molecular data from two mitochondrial genes (Cytochrome oxidase II and Cytochrome b) reported that the majority of Madagascan genera were not monophyletic, corroborating results from a previous morphological study [7]. Accordingly, the pre-existing genera Henotesia, Admiratio and Masoura were subsumed under Heteropsis as sub-genera, while Houlbertia was sunk completely $[8,18]$. The Afrotropical region now consists of three genera Heteropsis, Hallelesis and Bicyclus $[9,19]$. The genus Heteropsis Westwood (1850) comprises around 81 known species of which 46 are described and a further ca. 24 undescribed species are known in the Malagasy Region $[7,18,20]$. About 12 Heteropsis species are distributed in continental Africa [21-24] whilst Hallelesis, with two species, is confined to West and Central Africa [25]. Bicyclus consists of ca. 80 species in mainland Africa [9] with one species, B. anynana, also found in the Comoros [26]. Species-level relationships within the genus were investigated in a molecular study [27], for which data from three other mycalesine genera were used to root the tree. Although Bicyclus was eventually recovered as a clade, their sampling of other genera was too poor to establish firm support for its monophyly.
The remaining three genera (Mycalesis Hübner, 1818, Lohora Moore, 1880 and Nirvanopsis Vane-Wright, 2003) are found in the Indo-Australian tropics. Mycalesis is the most species-rich among current mycalesine genera with estimates of the number of species ranging from 87 to over 100 [28-31]. This genus is almost ubiquitously distributed in the Indo-Australian region ranging from Sri Lanka and India in the West, across IndoChina, South-East Asia and New Guinea, to North-East Australia and the Solomon Islands in the East. Lohora and Nirvanopsis are endemic to Sulawesi. Lohora contains 17 species and Nirvanopsis was for a long time considered to be monobasic (previously as Nirvana), but now includes a recently described species, $N$. susah. It has been suggested that Mycalesis is probably paraphyletic with respect to Lohora [31], and that Nirvanopsis might belong within Lohora [17]. Mycalesis was considered closely related to another Indo-Australian mycalesine genus Orsotriaena, but this has been refuted by recent molecular studies [32,33]. Mycalesis differs from Bicyclus by the presence of hairy eyes; dense interommatidal setae are absent in the latter [14]. Heteropsis also has hairy eyes [7] but differs from Mycalesis in details of wing venation and for most species, male genitalia [7]. Mycalesis was divided into several genera [12], and into species groups by [34] and [29]. Additional file 1 provides more information on taxonomical revisions and groupings of Asian and Australasian species.

The monophyly of genera and the relationships among them have strong implications for our understanding of their global diversification. Miller, whose study [11] was largely based on an examination of leg morphometrics, speculated that mycalesines started diverging in the Oriental region from an ancestor which was initially derived from Neotropical satyrines. According to his scenario, Africa was colonized twice, once by a naked eyed ancestor (leading to Bicyclus and Hallelesis) and by a hairy eyed ancestor that eventually went on to disperse into Madagascar (leading to Heteropsis) and went extinct in Africa. Miller further speculated that the hairy-eyed mycalesines dispersed into the Australasian region. Based on their tree where the African Heteropsis was nested within the Madagascan clade, Torres and colleagues [8] suggested an alternate scenario where Africa was colonized at least once from Madagascar.

Hostplant records for this group are scarce; the known records are mainly from Poaceae, but also from Cyperaceae, Marantaceae and Zingiberaceae [35]. Most regional groups tend to be restricted to the forested tracts of lower altitudes [10,36,37], whereas in some regions such as Madagascar there is elevational zonation along the entire forest gradient [38]. Mycalesines are generally low flying butterflies with weak to moderate dispersal abilities [8,25,39] (although the Heteropsis subgenera 
Masoura and Admiratio are canopy species, as is Nirvanopsis) $[40,41]$. This low dispersal ability along with habitat and bioclimatic fidelity renders several species endemic to narrow regions $[10,40]$. With some exceptions, species are dull and cryptically coloured, bearing a postdiscal series of eyespots (ocelli) on the dorsal and ventral surfaces that are sometimes not expressed on some wing surfaces or in both sexes. Species that experience defined periods of wet and dry seasons have a corresponding dry- and wet-season form [42]. This polyphenism is characterized by the reduction of the ventral eyespots in the dry season morph.

Mycalesines have been used extensively in various ecological (e.g. $[12,40,43,44])$ and evolutionary studies (e.g. [45-50]). Bicyclus in particular has carved a niche for itself as a model organism in evolutionary biology, with the eyespots in $B$. anynana having been the focus of innumerable evo-devo studies (e.g. [51-54]). Almost all species of Mycalesina possess eyespots, but, again, the lack of robust phylogenies has hindered comparative studies within a phylogenetic framework; the two studies on Bicyclus [50], and [55], are the only such studies so far.

No molecular study has incorporated sufficient species from all mycalesine genera for a rigorous test of their reciprocal monophyly. The two studies [8,27] were focused on regional mycalesine faunas. The former study did include a sample of the type species of Mycalesis, $M$. francisca, but found no support for its placement. These authors concluded that denser taxon sampling was necessary to elucidate generic level relationships within the group. In this study, we attempt to infer the phylogeny of Mycalesina using sequence data from three genes. We also include 42 species of Mycalesis and seek to identify major lineages within the genus and their relationships. We estimate lineage divergence times within the group and attempt to reconstruct events in its biogeographic history.

\section{Results}

\section{Systematics}

The combined dataset included 3139 base pairs (bp) from 125 samples including seven outgroups. The MP (Maximum Parsimony) analysis of the combined dataset resulted in 80 equally most parsimonious trees, the strict consensus of which is shown in Fig 1. The ML (Maximum Likelihood) analysis on the same dataset resulted in a topology that differed at several nodes (Fig 2). However, these differences were mainly in the basal nodes that were weakly supported in both analyses, and in the ML tree, preceded by short branches. Nodes that were well supported ( $>80 \%$ bootstrap values) in the ML analysis also figured in the MP topology, albeit with lower support in general. Both analyses supported the monophyly of Mycalesina (MP: 98\% bootstrap; ML: $100 \%$ bootstrap). The BI (Bayesian Inference) tree was different to both MP and ML, but incongruence was restricted mainly to the basal part of the tree (Fig 3). Nodes supported strongly in the ML analysis were recovered with strong posterior probabilities in the BI tree. Results that are consistent across the three tree-building methods are elaborated below.

Bicyclus, Hallelesis and Nirvanopsis emerged as monophyletic groups in all three analyses whereas the remaining genera were either paraphyletic or polyphyletic. The monophyly of Bicyclus was strongly supported in the model-based analyses but only moderately so in MP. Hallelesis and Nirvanopsis, each represented by two species, were monophyletic with strong support. Nirvanopsis was nested within Lohora, rendering the latter paraphyletic. Relationships among Heteropsis species were broadly consistent with subgeneric groupings in [7]. A group consisting of $M$. adolphei, M. janardana, M. sangaica, M. mamerta and M. malsara was nested within Heteropsis. The remaining Mycalesis species clustered into two clades, but Mycalesis as a whole was polyphyletic.

Six higher clades within Mycalesina were common to all three analyses, each with moderate to strong support in the model-based analyses, but weaker support in MP. These will be referred to as the stable clades and have been named either with novel or available names to facilitate discussion (Figs 1, 2 and 3). Relationships within these stable clades were similar, if not congruent, between analyses (an exception is the unresolved nature of Mycalesis clade II in MP). Some previously recognised species groups (Additional file 1) in Mycalesis were also recovered as well-supported clades. The Mineus group of Evans (2-species group of Aoki and colleagues [29]; approximating to Calysisme of Moore plus Jatana) was one such group, which includes $M$. mynois, $M$. perseus, M. mineus, M. intermedia, M. perseoides and M. visala. $M$. perseus is the most widely distributed Mycalesis species, ranging from the Indian subcontinent to NE Australia. The other members of the Mineus group are restricted to the Oriental region. M. patnia ('4-species' group of Aoki and colleagues [29]) was either nested within or sister to the '1-species' group (including $M$. gotama, M. patnia, M. orseis, M. francisca and $M$. anaxias; equivalent respectively to Moore's Sadarga, Nissanga, Suralaya, Gareris and Virapa). Members of these three species groups together formed a stable clade, which will be referred to as Mycalesis clade I.

The Australasian species (M. barbara, M. aethiops, M. mucia, M. phidon, M. mehadeva, M. cacodaemon, M. sirius, M. duponchelii, M. discolobus, M. elia, M. terminus, M. mulleri, M. splendens, M. interrupta, M. biliki, $M$. richardi and $M$. sara) in addition to the Oriental 


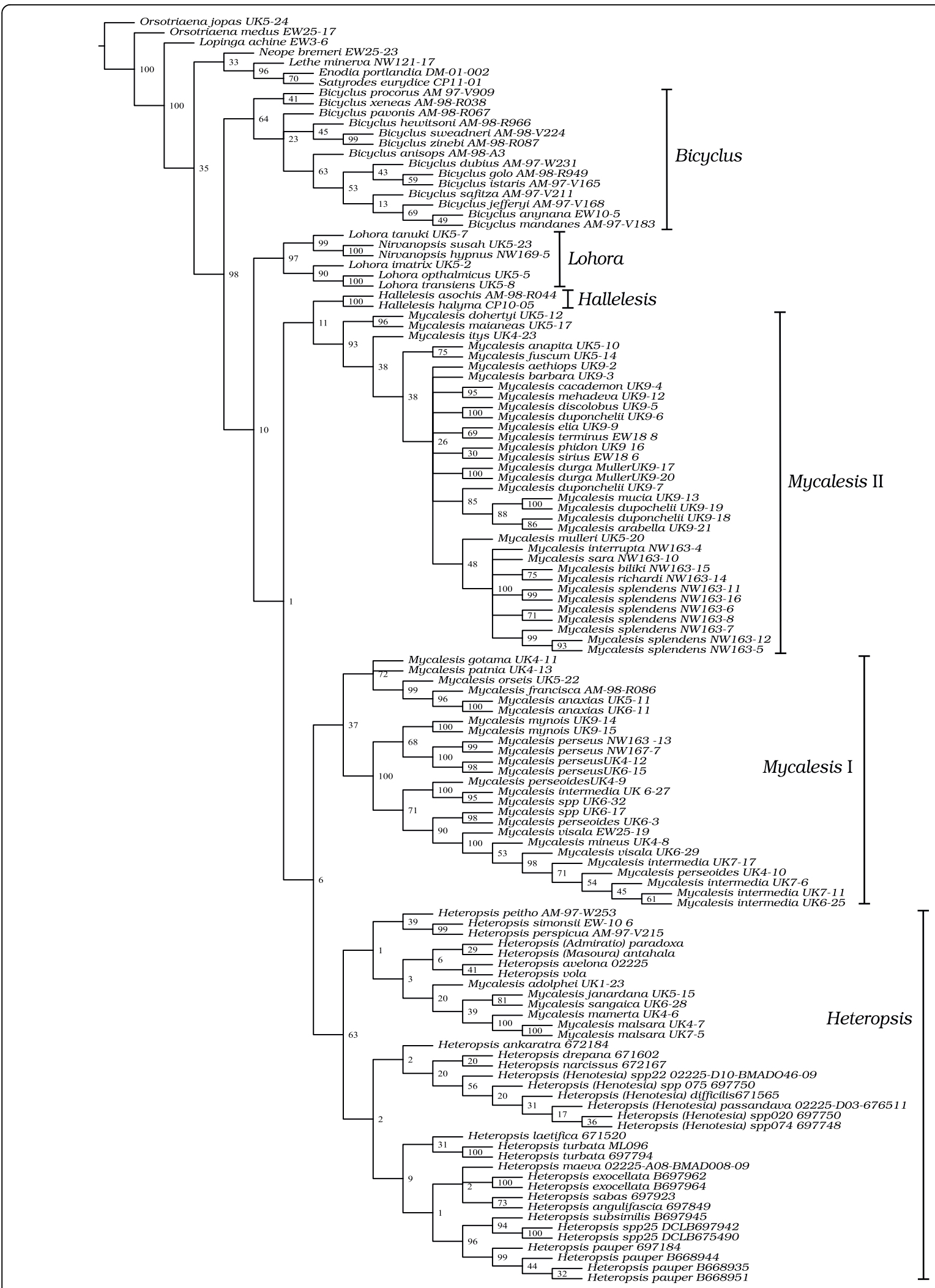

Figure 1 Strict consensus topology of the $\mathbf{8 0}$ equally most parsimonious trees recovered in the Maximum Parsimony analyses of the combined dataset in TNT (Length $=\mathbf{7 2 9 0}$ ). Numbers indicate bootstrap support for nodes. Names of the six 'stable clades' identified in this study are indicated next to the taxon names (see Results section). 


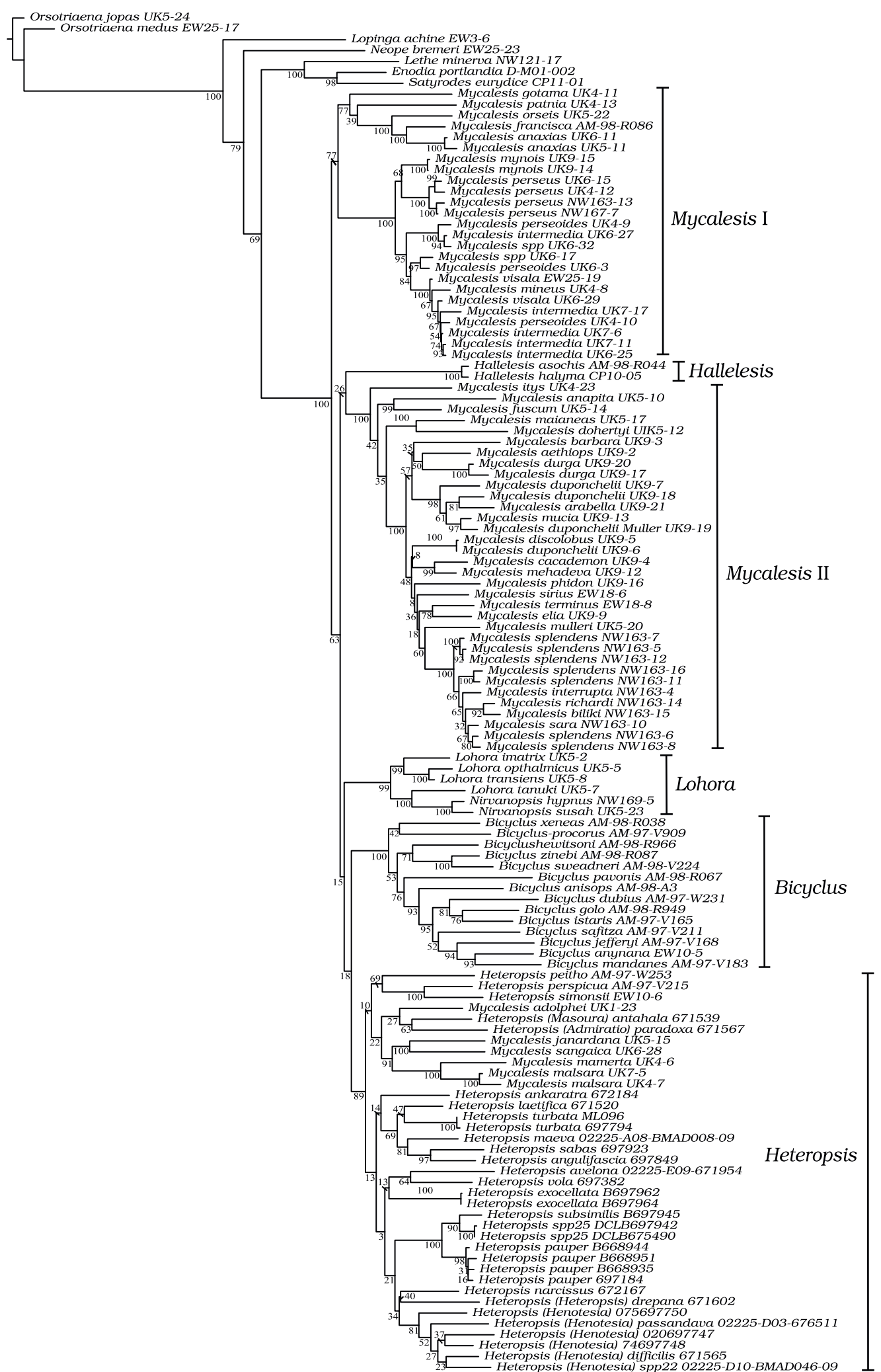

Figure 2 Maximum Likelihood topology recovered from the RAxML analysis of the combined dataset. Numbers indicate bootstrap support for the nodes to the right. Names of the six 'stable clades' identified in this study are indicated next to the taxon names (see Results section). 


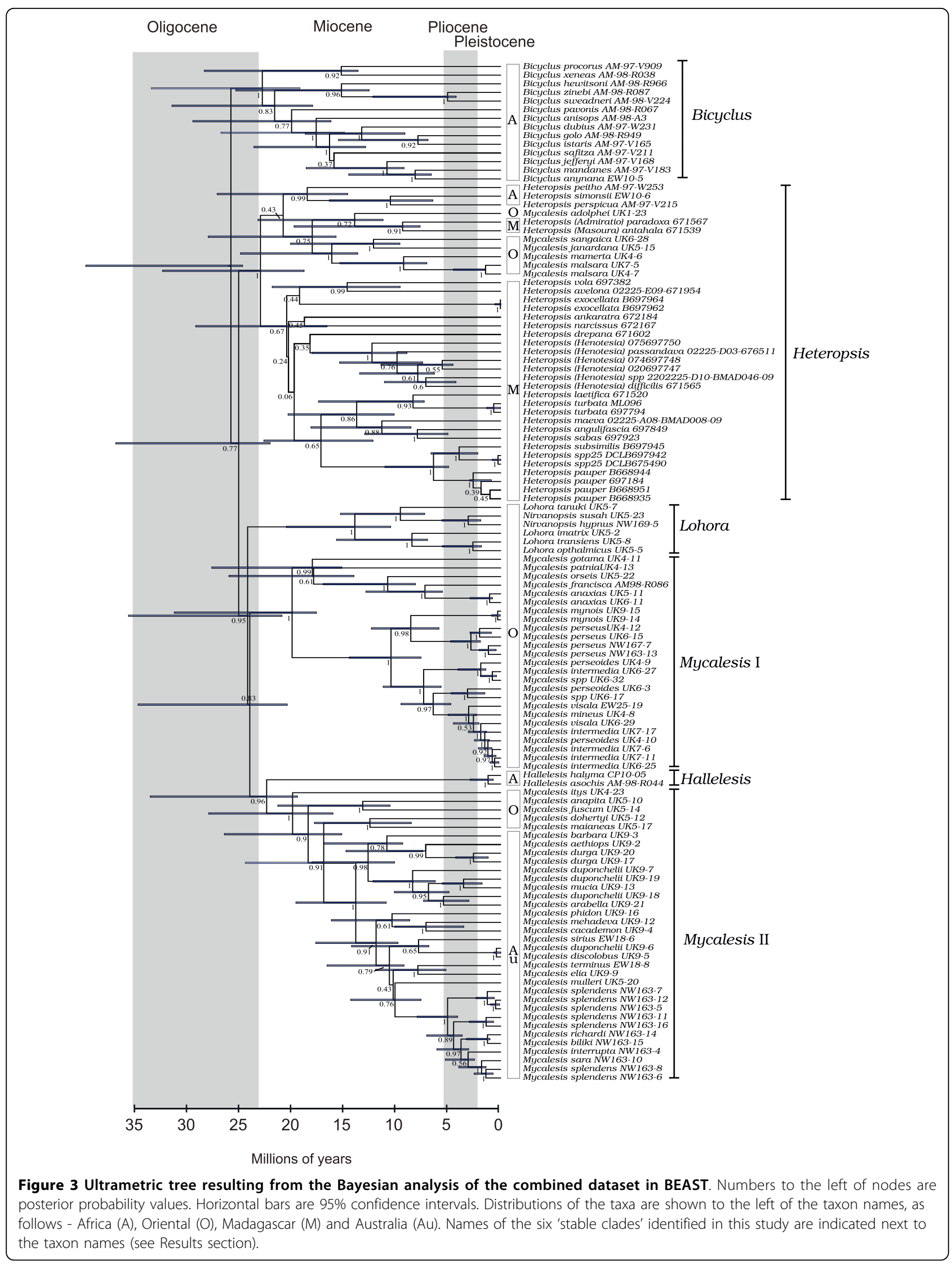


M. dohertyi, M. maianeas, $M$. itys, $M$. fuscum and $M$. anapita formed another stable clade, hereafter referred to as Mycalesis clade II (equivalent to Mydosama of Moore plus Savanda, Nebdara, Satoa and possibly Culapa). The Oriental genera within the clade were basal members, while the Australasian species were a strongly supported clade nested within. The other stable clades within Mycalesina are Lohora (Lohora + Nirvanopsis), Hallelesis, Bicyclus and Heteropsis (including some species of Mycalesis; Fig 1, 2 \&3).

ML analysis on the COI dataset recovered the six stable clades (Additional file 2). Mycalesis clade II was nested within Mycalesis clade I in the EF-1 $\alpha$ tree, while the remaining four stable clades were retrieved (Additional file 3). The wingless tree was generally poorly-supported with very short branches, but recovered the Heteropsis and Lohora clades (Additional file 4). Hallelesis and Bicyclus were represented by a single species, whereas Mycalesis clades I and II were not monophyletic.

\section{Shimodaira-Hasegawa tests}

The likelihood score of the ML topology in Fig 2 (In $L=$ -38610.95571) was significantly higher than the "genus monophyly" topology ( $\ln L=-38702.28514)$, wherein each genus was constrained to be monophyletic ( $\mathrm{P}=$ 0.002 , Shimodaira-Hasegawa test, Table 1). On the contrary, there was no significant difference in likelihood scores between the ML topology and the tree where Mycalesis clades I and II were reciprocally monophyletic.

\section{'Rogue' analysis}

Each of the six stable clades was successively removed and the resulting datasets subjected to RaxML analyses. The resulting trees are summarized in Additional file 5. We found that deleting any of the clades did not increase support for basal nodes; nodes with $<50 \%$ bootstrap values did not receive $>50 \%$ support.

\section{Divergence time estimates}

The dating analysis in BEAST indicates that the ancestors of the six stable clades diverged between 26 and 21 mya (Fig 3) Initial splits within the Lohora, Bicyclus, Mycalesis groups I and II began ca. 18-20 mya. The two species of Hallelesis started diverging ca. 1.5 mya.

Table 1 Results of Shimodaira-Hasegawa tests (see text for details)

\begin{tabular}{cccc}
\hline Topology & $-\ln \mathbf{L}$ & Difference - In L & P value \\
\hline ML & 38610.96 & - & - \\
\hline GM & 38702.298514 & 91.33 & $0.002^{*}$ \\
\hline MM & 38624.71 & 13.76 & 0.47 \\
\hline
\end{tabular}

${ }^{*} \mathrm{P}<0.05$. ML: unconstrained ML tree in Fig 2. GM: "genus monophyly" topology where each genus was constrained to be monophyletic. MM: Topology where Mycalesis clade I and II were reciprocally monophyletic.

\section{Discussion}

Although we found several well-supported higher clades within Mycalesina that were stable with respect to the method of analysis, relationships between these clades varied considerably between the analyses. Some of the instability could perhaps be due to missing data for some taxa. However, incongruent relationships were those that were supported poorly in all analyses, which suggests that the conflict between the methods is due to poor phylogenetic signal in the dataset. We believe that the basal divergences have happened in rapid succession with little time for synapomorphic changes to accumulate in the intervening period between two successive splits [56,57]. This pattern is similar to that reported in other satyrine groups [58,59]. Increasing the number of genes has been shown to improve resolution of rapid radiations in some cases, whilst some nodes remained poorly supported despite adding data from multiple genes [60-62]. The synergistic effect of the addition of morphological data to molecular datasets has been demonstrated before [63]. However, morphology has not proved satisfactory for the higher level classification of the group and it remains to be seen whether addition of morphological characters will resolve basal relationships, though we suspect that these nodes will be difficult to resolve.

Although basal relationships are unresolved by the current data we do find several well-supported evolutionary groups. The results call for major redefinitions of mycalesine genera as well as illuminate aspects of the biogeographic history of the group.

\section{Systematic implications}

We propose that the group of Mycalesis species nested within Heteropsis should henceforth be classified under Heteropsis. Mycalesis clades I and II were never sister to each other in the combined analyses, although a topology with Mycalesis clades I and II constrained to be sister to each other was not significantly worse than the ML topology (where they are not sister to each other). Nevertheless, we propose that members of clade I and II should be classified under two respective genera. The genetic divergence between the clades is comparable to the divergence between other genera in our study, supporting our re-classification scheme. Furthermore, the two clades almost completely allopatric, with clade I restricted to South and SE Asia, whereas clade 2 is predominantly Australasian. Moreover, even under the unlikely event that these two clades indeed turn out to be each others' sisters with strong support, our proposed classification system would still remain valid. Clade I includes the type species of the genus ( $M$. francisca) and we propose that members of this clade should be classified under Mycalesis sensu stricto. We transfer the species in the Mycalesis Clade II to Mydosama (type 
species, Dasyomma fuscum Felder \& Felder, 1860). We also subsume Nirvanopsis under Lohora.

\section{Biogeography}

It is important to bear in mind that our divergence time estimates are based on a single secondary calibration point (from [64]) and as such are a first approximation. We here present our interpretation of the biogeographic history of the group based on these timing estimates and the strongly supported monophyletic groupings. The age of the most recent common ancestor of Mycalesina suggested by the dating analysis precludes a Gondwanan origin of the group. The most likely sister clade of the group is composed of a group of genera distributed predominantly in the Oriental and the easternmost parts of Palaearctic region [59,64]. Miller's hypothesis [11] was that the ancestor of mycalesines was of Oriental origin and the group diversified through dispersals to the Afrotropical and Australasian regions. Mycalesis clade I emerged sister to remaining mycalesine clades in the ML tree, in support of Miller's hypothesis. However, the MP and BI trees retrieved the African Bicyclus as sister to the rest of the mycalesines, although without strong support for the latter group. This would point to an African origin, as already shown in two other nymphalid groups, Junonia and Charaxes $[6,65]$. In this scenario, mycalesines started evolving in Africa, with subsequent colonization of Madagascar where there was explosive radiation of the Heteropsis group, and this group subsequently invaded Asia. With the poorly supported basal relationships, however, we are unable to distinguish between hypotheses of African and Asian origin. Nonetheless, it is clear that there has been at least one dispersal event between the AfroMalagasy and Asian regions in the early evolution of the group. This colonization(s) has most likely occurred across the Arabian Peninsula, which is thought to have been covered by forests at some point during the Miocene $[66,67]$. The Arabian Peninsular region appears to have been important for butterflies as a corridor of 'geodispersal' (concordant dispersal of several lineages over the same route) [68] between Africa and Asia.

The grouping of some Asian mycalesines with the Afro-Malagasy genus Heteropsis is well supported by all combined analyses and independently by the COI and EF-1 $\alpha$ datasets (note that the close relationship of M. adolphei with Heteropsis is also supported by morphological data, in particular the form of the male genitalia; $[7,18])$. This grouping suggests at least one dispersal event from the Afrotropical to the Oriental Region, as the Oriental members are derived within the Heteropsis group. Our trees also suggest tentatively (although lacking support for the placement of Admiratio + Masoura) that the Madagascan mycalesines comprise two independent radiations (subgenera Admiratio+Masoura, and the clade including subgenera Heteropsis + Henotesia). Greater taxon and gene sampling (note that Admiratio and Masoura are only represented in our tree by COI) is therefore needed to establish a robust topology for Heteropsis sensu lato that can lead to a stronger inference of the biogeographic history of the group. It is very probable that two species ( $H$. comorana and $H$. narcissus) have colonised the Comoros and Mascarenes from Madagascar [18,26]. However, only one recent colonisation event is suggested from Africa; the secondary colonization of the species B. anynana of Comoros [256].

Sulawesi has been colonised at least twice independently early in the evolution of Mycalesina (between ca. 24-19 mya), by the ancestors of the Lohora clade and of $M$. itys. Interestingly, while Lohora has radiated into 19 species, the ancestor of $M$. itys seems not to have undergone in situ speciation within the island ( $M$. itys is the only Mycalesis species endemic to Sulawesi).

The endemic Australasian fauna share a common ancestor that was derived from the Oriental region. This ancestor diversified rapidly in New Guinea, with the first splits occurring ca. 15 mya. The endemics in the Solomon Islands (biliki-splendens-richardi-interrupta-sara) descend from an ancestor derived from New Guinea in the Late Miocene. M. terminus and M. sirius (Mycalesis II clade) expanded their range into Australia from New Guinea while $M$. perseus (Mycalesis I clade), has colonized Australia and the Solomons between 1 and 2 mya.

\section{Ecology and evolution}

Although some mycalesine faunas, such as that now represented as Clade I of SE Asia, tend to be rather brownish or homogeneous in colour pattern, this is not the case everywhere. The endemics in the Australasian region and the Lohora clade of Sulawesi include more colourful members, and may even be mimetic; in the case of Mycalesis drusillodes so spectacularly that they had been described as different species, the male mimicking a Tellervo and the female a Taenaris $[13,14]$. The Malagasy fauna, in particular, is exceptionally diverse in wing pattern and wing shape. There is also evidence for mimicry between different clades of Heteropsis in Madagascar and between Heteropsis (Masoura) masoura (in this case sexually monomorphic) and the aposematic pierid Mylothris phileris [7]. Dead leaf mimicry is also evident in the Malagasy Heteropsis drepana. The significance of these regional differences in colour pattern and form in different faunas perhaps relates to aspects of the environment, notably differing suites of predators [69], but there is to date no experimental evidence of their role. In Madagascar, mycalesines occurring in open areas 
or on margins of forests are markedly more orange rather than brown [7].

This remarkable inter-specific diversity in wing patterns may also have been mediated, at least partially, by sexual selection. It has been shown experimentally that eyespots on the dorsal surface of $B$. anynana are used by females to choose mates $[47,48]$. Pronounced sexual dimorphism occurs in some African Bicyclus, and especially within the Heteropsis subgenus Henotesia in Madagascar, another case extreme enough that females had not been been matched to males, neither had different seasonal stages of males been correctly synonymised (but see $[7,70])$. Wing patterns are known to have sexspecific evolutionary rates within Bicyclus [50]. All these lines of evidence point towards sexual selection as an additional mediator of morphological diversification. Results in [50] also suggested that mate signalling selects for varying dorsal wing patterns while ventral characters are selected upon by predation pressure. Thus, a complex interaction of differential selective forces along with the heterogeneity of environments inhabited by these species seems to have driven the morphological diversification of wing patterns in this group, and much needs to be learnt about the systems.

The most striking aspect of diversification that may be related to speciation in mycalesine butterflies is in the scent organs, which are exceptionally diverse, including male androconia on forewing underside, hindwing upperside, abdominal underside and upperside, specialized wing veins, and specialized polished areas that may have protective function [7]. These androconia are known to release male sex pheromones during courtship, which are crucial determinants of reproductive isolation between species [71,72]. Even to humans, mycalesine scent brushes differ in odour [7]. A denser sampling is needed to test whether the exceptional diversification of androconia is related to elevated levels of speciation in this group. Our phylogeny provides a starting point to identify groups that can be used for further comparative analyses that seek to understand the underlying processes that might have generated these diverse characters.

From a biogeographic perspective, the moderate to weak dispersive powers of mycalesine butterflies explains some of their diversity, because poor dispersive power is expected to be conducive towards higher rates of allopatric speciation [73]. Dispersal into a novel area is more likely to result in allopatric speciation compared to a group with high vagility that can maintain regular geneflow [73]. Vicariance events are also more likely to result in speciation when the ancestor in question has weak dispersive powers. For instance, the aridification of central India during the Pliocene may have resulted in vicariant events that left descendant sister species pairs disjunct in South-West India and North-East India [74]. Unfortunately, we are unable to test this hypothesis with our limited taxon sampling.

The radiation of Satyrini (Satyrinae) butterflies, to which Mycalesina belongs, is thought to have closely followed the diversification of $\mathrm{C}_{4}$ grasses during the Oligocene [33]. Host-plant mediated speciation can occur due to episodes of host-expansion and specialization during the history of the group [75,76]. The degree of specialization of satyrines on their grass host plants is unknown, but Mycalesis is one satyrine group where host-plant preference hierarchy and specialization has been reported [77]. A rigorous test of the hypothesis that mycalesines radiated by co-evolving with their grass hostplants is, however, hindered by the lack of reliable host plant records for most mycalesines.

We surmise that a combination of several factors androconial diversification, sexual selection on wing patterns, moderate dispersive powers, and perhaps also co-evolution with grasses - has resulted in the high diversity of species in the group. In summary, this group of butterflies presents an exciting opportunity to understand patterns and processes of diversification in insects, especially in unravelling the complex interactions among various selective forces and developmental aspects of wing patterns. The phylogeny encompassing the entire radiation and nomenclatural rationalisation at a generic level presented here is the first step that will eventually permit large-scale analyses to explore specific hypotheses within a comparative framework.

\section{Conclusions}

Our phylogenetic hypothesis based on three genes indicates that Mycalesina radiated rapidly during the Oligocene-Miocene boundary. Their origin is as yet unclear, and may be either in Asia or Africa, but they have undergone dispersals between the two regions. Our topology implies that Madagascar was colonized at least twice, resulting in independent radiations, but it is not yet certain if its role as a source area was limited to colonisation of neighbouring islands. More clearly, the Australasian mycalesine fauna have radiated following a single dispersal event to the region. We propose a radically new classification of the group and discuss factors likely to have played a key role in their diversification. Our phylogeny paves the way for exciting comparative studies that will help us understand the process of diversification of rapid radiations.

\section{Methods}

\section{Data collection}

Specimens of 42 species of Mycalesis, 28 of Heteropsis, four of Lohora and two of Nirvanopsis were collected either by the authors or collaborators at different times 
between 2001 and 2008. 13 widespread species were represented by more than one sample. DNA was preserved either through dessication or by immersing two legs in alcohol. Once the samples reached the lab, DNA was extracted from two legs using the DNEasy extraction kit (QIAgen). DNA was amplified from three gene regions - 1450 bp (base pairs) of COI (cytochrome oxidase subunit I), a mitochondrial gene, and two nuclear genes - EF-1 $\alpha$ (Elongation Factor 1 alpha; $1240 \mathrm{bp}$ ) and wingless (400 bp). The gene trio has been successful in resolving relationships of species within a genus in several nymphalid studies [65,78-81].

Readers are referred to [82] for a list of primer sequences used here. COI was amplified using the primer pairs LCO-HCO and Jerry-Pat. Three primer pairs were used for EF-1 $\alpha$ - Starsky-Luke, Cho-Verdi and EF51.9-EFrcM4, while LepWing1 and LepWing2 or Wingnut 1A (5'-GAA ATG CGN CAR GAR TGY AA3') and Wingnut-3 (5'-ACY TCR CAR CAC CAR TGR AA-3') were used for wingless. The PCR protocol used for Starsky-Luke was as follows $-95^{\circ} \mathrm{C}$ for $7 \mathrm{~min}$, 40 cycles of $95^{\circ} \mathrm{C}$ for $30 \mathrm{~s}, 55^{\circ} \mathrm{C}$ for $30 \mathrm{~s}$ and $72^{\circ} \mathrm{C}$ for $1 \mathrm{~min}$ followed by a final extension period of $72^{\circ} \mathrm{C}$ for $10 \mathrm{~min}$. For Wingnut $1 \mathrm{~A}-\mathrm{Wingnut} 3$, conditions were $80^{\circ} \mathrm{C}$ for $1 \mathrm{~min}, 40$ cycles of $94^{\circ} \mathrm{C}$ for $1 \mathrm{~min}, 46-52^{\circ} \mathrm{C}$ for $2 \mathrm{~min}$ and $72^{\circ} \mathrm{C}$ for $1-2 \mathrm{~min}$ followed by a final extension period of $72^{\circ} \mathrm{C}$ for $10 \mathrm{~min}$. For the remaining five primer pairs, we used the following protocol: $95^{\circ} \mathrm{C}$ for 7 min, 40 cycles of $95^{\circ} \mathrm{C}$ for $30 \mathrm{~s}, 50^{\circ} \mathrm{C}$ for $30 \mathrm{~s}$ and $72^{\circ} \mathrm{C}$ for $1 \mathrm{~min}$ followed by a final extension period of $72^{\circ} \mathrm{C}$ for $10 \mathrm{~min}$. Successfully amplified PCR products were sequenced with a Beckmann-Coulter CEQ8000 automated sequencer. The resulting chromatograms were visualized in BioEdit v7.0.5.3 [83] and aligned by eye. We also included sequence data from the genera Bicyclus, Heteropsis and Hallelesis that were available on Genbank. Outgroup data were taken from [32]. Additional file 5 lists the samples used in this study with their collection localities and Genbank accession numbers for respective sequences.

\section{Phylogenetic inference}

The combined dataset was analyzed under the maximum parsimony (MP) criterion in TNT v 1.1 [84]. Heuristic searches including traditional TBR branch swapping procedures and 'New Technology' searches were performed on 1000 random addition replicates. Support for respective clades was estimated using bootstrap values calculated from 1000 pseudo-replicates with 10 replicates each. Maximum likelihood (ML) analyses were performed in RAxML III [85] with default heuristic search algorithms. The GTR+G model, which was chosen by jModelTest [86] under the Akaike Information Criterion, was imposed on the three gene partitions independently with the gamma parameter estimated in 4 discrete rate categories. Bootstrap values were calculated from 1000 pseudo-replicates. Since some samples did not have a complete three-gene dataset (Additional file 6), ML analyses were performed on individual gene datasets excluding samples missing data for respective genes. Individual gene analyses also allow us to assess nodal support from each gene.

We performed Shimodaira-Hasegawa tests [87] to test whether specific topologies resulting from the above analyses were significantly better than competing topologies. The program MacClade [88] was used to construct two constraint trees; in the first tree each genus were forced to be monophyletic and in the second tree only species in Mycalesis clades I and II (see results) were placed in a monophyletic group, while the position of other species remained unconstrained. These constraint trees were used in PAUP* [89] to derive a "genus monophyly" tree and "Mycalesis monophyly" tree through a likelihood heuristic search. To examine support for the above hypotheses the likelihood scores of these trees were compared with the unconstrained $\mathrm{ML}$ tree using the one-tailed Shimodaira-Hasegawa log-likelihood test as implemented in PAUP*, using the re-sampling estimated log-likelihood (RELL) technique approximation with 10,000 bootstrap replications. These analyses were implemented on the combined dataset.

We also conducted a 'rogue' analysis to test whether there was one or more 'rogue' clades that was leading to the observed low basal support values. Each of the six 'stable' clades identified in the Results section was successively removed and the datasets analysed in RaxML with bootstrapping to test whether deletion of one of these clades resulted in stronger support.

\section{Estimate of divergence times}

We used the software BEAST v 1.4.8 [90] for Bayesian inference (BI) of phylogenetic relationships and divergence times simultaneously. The analysis was carried out without outgroups since BEAST does not rely on outgroups to root the tree; instead it uses a relaxed molecular clock. The "treeModel.RootHeight" prior (i.e., the age at the root of the tree) was set to a normal distribution with a mean of 27 million years and a standard deviation of 3. This date was taken from [64] which studied the divergence times within Nymphalidae based on a 10-gene dataset from $>400$ genera (including Mycalesis, Bicyclus, Hallelesis and Heteropsis), with both minimum and maximum calibration points. The dataset was partitioned into nuclear (EF-1 $\alpha$ and wingless combined) and mitochondrial (COI) genes, with parameter values estimated independently for each partition. The GTR+G model was imposed with a relaxed clock where branch lengths were allowed to vary according to an uncorrelated lognormal 
distribution [91]. The tree prior was set to the BirthDeath process, while all other priors were left to their defaults in BEAST. The analysis was run twice for $10,000,000$ generations of MCMC analyses in BEAST and the chains were sampled at every 1,000 generations, yielding a total of 10,000 samples for each run. Whether the parameter estimates and tree topology were at equilibrium was determined by using the program Tracer [91]. The first 1,000,000 generations (or 1000 trees) were discarded as burn-in.

\section{Additional material}

Additional files 1: Appendix 1. List of genera under which Mycalesis was divided under by Moore (1880), and the species groupings of Evans (1932) and Aoki et al (1982).

Additional file 2: Appendix 2. Maximum Likelihood topology recovered from the RAxML analysis of the COI dataset. Numbers indicate bootstrap support for the nodes to the right.

Additional file 3: Appendix 3. Maximum Likelihood topology recovered from the RAxML analysis of the EF-1 $\alpha$ dataset. Numbers indicate bootstrap support for the nodes to the right.

Additional file 4: Appendix 4. Maximum Likelihood topology recovered from the RAxML analysis of the wingless dataset. Numbers indicate bootstrap support for the nodes to the right.

Additional file 5: Appendix 5. Maximum Likelihood topologies recovered in RAxML analyses where each of the six stable clades were successively removed from the dataset. Numbers indicate bootstrap support for the nodes to the right. a) minus Bicyclus, b) minus clade 1, c) minus Mycalesis clade 2, d) minus Hallelesis, e) minus Heteropsis, f) minus Lohora.

Additional file 6: Appendix 6. List of taxa used in this study with their Genbank accession numbers. An asterix after the name indicates that wingless for that species was sequenced from a different individual of the same species. A double asterisk indicates that the taxon was an outgroup. Collection localities are mentioned for all samples collected for the purpose of this study.

\section{Acknowledgements}

We acknowledge financial support from the Academy of Finland (grant no. 118369; to NW), the Swedish Research Council (to NW), the Department of Biotechnology (Ministry of Science and Technology, India, BT/PR8355/NDB/ 51/142/2006; to KPK). The Karnataka Forest Department provided permits for collecting specimens in Karnataka, India. Vahan W. Kassabian sequenced wingless for some taxa; that work was funded by the Cea-CREST program at California State University, Los Angeles (NSF HRD 9805529). Paul Goldstein and Rob Desalle provided Wingnut primer sequences. A few $\mathrm{COI}$ sequences were provided by Canadian Centre for DNA barcoding (Univ. Guelph). DCL benefited from a STUDIUM fellowship during the writing of this paper. The Malagasy authorities including Mme Olga Ramilijaonat (Univ. Antananarivo) and MICET are thanked for various collection permits (to DCL and Claire Kremen). Funding for Malagasy collection was also provided by the Leverhulme Trust (F/00696/I), National Geographical Society (grant \# 733202) and BBSRC (93307999) to Robert K. Wayne. UK received a travel grant from K \& A Wallenbergs Stiftelse for field work. Alexander Monastyrskiy helped identify some samples. Antónia Monteiro kindly provided some Bicyclus sequences used here.

\section{Author details}

'Department of Zoology, Stockholm University, 10691 Stockholm, Sweden. ${ }^{2}$ Department of Entomology, Natural History Museum, London, UK. ${ }^{3}$ Centre de Recherche d' Orléans, INRA, UR 633 Zoologie Forestière, F-45075, Orléans, France. ${ }^{4}$ Molecular Ecology Lab, Department of Biological Sciences,
Macquarie University, Sydney, NSW 2109, Australia. ${ }^{5}$ Department of Biological Sciences, California State University, Los Angeles, CA 90032 USA. ${ }^{6}$ Center for Ecological Sciences, Indian Institute of Sciences, Bangalore, India. 'Laboratory of Genetics, Department of Biology, University of Turku, 20014 Turku, Finland.

\section{Authors' contributions}

UK and NW conceptualized and coordinated the study, with the former doing a major part of the lab work. DCL, PK, ET and NW provided sequence data while CJM collected most of the samples from the Australasian region used here. The manuscript was drafted by UK with active participation from the rest of the authors. All authors read and approved the final manuscript.

Received: 22 January 2010 Accepted: 10 June 2010

Published: 10 June 2010

\section{References}

1. Boggs CL, Watt WB, Ehrlich PR: Butterflies: Evolution and Ecology Taking Flight. Chicago, USA: University of Chicago Press 2003.

2. Mallarino R, Bermingham E, Willmott KR, Whinnett A, Jiggins CD: Molecular systematics of the butterfly genus Ithomia (Lepidoptera: Ithomiinae): a composite phylogenetic hypothesis based on seven genes. Molecular Phylogenetics and Evolution 2005, 34:625-644.

3. Silva Brandão KL, Wahlberg N, Francini RB, Azeredo-Espin AML, Brown KS Jr, Paluch M, Lees DC, Freitas AVL: Phylogenetic relationships of butterflies of the tribe Acraeini (Lepidoptera, Nymphalidae, Heliconiinae) and the evolution of host plant use. Molecular Phylogenetics and Evolution 2008, 46:515-531.

4. Megens HJ, van Nes WJ, van Moorsel CHM, Pierce NE, de Jong R: Molecular phylogeny of the Oriental butterfly genus Arhopala (Lycaenidae, Theclinae) inferred from mitochondrial and nuclear genes. Systematic Entomology 2004, 29:115-131.

5. Aduse-Poku K, Vingerhoedt E, Wahlberg N: A phylogenetic hypothesis of the genus Charaxes (Lepidoptera: Nymphalidae) based on 5 gene regions. Molecular Phylogenetics and Evolution 2009, 53:463-478.

6. de-Silva DL, Day JJ, Elias M, Willmott K, Whinnett A, Mallet J: Molecular phylogenetics of the neotropical butterfly subtribe Oleriina (Nymphalidae: Danainae: Ithomiini). Molecular Phylogenetics and Evolution 2010, 55:1032-1034.

7. Lees DC: Systematics and Biogeography of Madagascan Mycalesine Butterflies (Lepidoptera: Satyrinae). PhD thesis London: University of London 1997.

8. Torres E, Lees DC, Vane-Wright RI, Kremen C, Leonard JA, Wayne RK: Examining monophyly in a large radiation of Madagascan butterflies (Lepidoptera: Satyrinae: Mycalesina) based on mitochondrial DNA data. Molecular Phylogenetics and Evolution 2001, 20:460-473.

9. Condamin M: Monographie du Genre Bicyclus (Lepidoptera: Satyridae). Dakar: IFAN 1973, 88.

10. Corbet AS, Pendlebury HM: The Butterflies of the Malay Peninsula. Kuala Lumpur: Malayan Nature Society, 41992.

11. Miller LD: The higher classification, phylogeny and zoogeography of the Satyridae (Lepidoptera). Memoirs of the American Entomological Society 1968, 24:1-174.

12. Moore F: On the Asiatic Lepidoptera referred to the genus Mycalesis; with descriptions of new genera and species. Transactions of the Entomological Society of London 1880, 28(4):155-177.

13. Vane-Wright RI: The systematics of Drusillopsis Oberthür (Satyrinae) and the supposed amathusiid Bigaena van Eecke (Lepidoptera: Nymphalidae), with some observations on Batesian mimicry. Transactions of the Royal Entomological Society of London 1971, 123:97-123.

14. Vane-Wright Rl: Further observations on the occurrence and mimicry of Mycalesis drusillodes (Lepidoptera: Nymphalidae, Satyrinae). Journal of Entomology (B) 1974, 42:213-216.

15. Parsons M: The Butterflies of Papua New Guinea: Their Systematics and Biology. London: Academic Press 1998.

16. Aurivillius C: Rhopalocera Aethiopica. Stockholm/Uppsala, Sweden: Arkiv for Zoologi 1898.

17. Vane-Wright Rl, Fermon H: Taxonomy and identification of Lohora Moore (Lepidoptera: Satyrinae), the Sulawesi bush-browns. Invertebrate Systematics 2003, 17:129-141. 
18. Lees DC, Kremen C, Raharitsimba H: Classification, Diversity and Endemism of the Butterflies (Papilionoidea and Hesperioidea): A Revised Species Checklist. The Natural History of Madagascar Chicago: University of Chicago PressGoodman SM, Benstead JP 2003, 762-793.

19. Williams MC: The Papilionoidea and Hesperioidea of the Afrotropical Region. CD-ROM. 2009, Available from the author at mark.williams@up.ac. za.

20. Lees DC, Minet J: Lepidoptera: Systematics and Diversity. The Natural History of Madagascar Chicago: University of Chicago PressGoodman SM, Benstead JP 2003, 748-761.

21. Usher MB: The species of Henotesia Butler (Lepidoptera: Nymphalidae, Satyrinae) in western West Africa. Entomologica Scandinavica 1985, 16:259-264.

22. Kielland J: A Revision of the Genus Henotesia (Excluding Madagascar and other Indian Ocean Islands) (Lepidotera Satyridae). Lambillionea 1994, 94(2, I):235-274

23. Van Son G: Butterflies of southern Africa. Part II. Nymphalidae: Danainae and Satyrinae. Transvaal Museum Memoirs 1955, 8:1-166.

24. Libert M: Note sur genre Henotesia Butler (Lepidoptera, Satyridae). Lambillionea 2006, CVI(1).

25. Larsen TB: Butterflies of West Africa. Stenstrup, Denmark: Apollo Books 2005.

26. Turlin B: Faune Lepidopterologique de l'Archipel des Comores (Océan Indien), (Rhopaloceres, Sphingidae, Attacidae). Lambillionea 1994, 94:81-94.

27. Monteiro A, Pierce NE: Phylogeny of Bicyclus (Lepidoptera: Nymphalidae) inferred from COI, COll, and EF-1alpha gene sequences. Molecular Phylogenetics and Evolution 2001, 18:264-281.

28. Fruhstorfer $\mathrm{H}$ : The Indo-Australian Rhopalocera. [Satyridae]. The Macrolepidoptera of the World: a systematic description of the hitherto known macrolepidoptera Stuttgart: Alfred KernenSeitz A 1911, 9:285-401.

29. Aoki T, Yamaguchi S, Uemura Y: Vol.III. Satyridae, Amathusiidae and Libytheidae. Butterflies of the South East Asian Islands 3 Tokyo: PlapacTsukada E 1982

30. Tennent WJ: A review of the genus Mycalesis in the Solomons archipelago, with descriptions of seven new taxa (Lepidoptera: Nymphalidae: Satyrinae). Tropical Lepidoptera 2001, 12(1).

31. Vane-Wright Rl, de Jong R: The butterflies of Sulawesi: annotated checklist for a critical island fauna. Leiden: Nationaal Natuurhistorisch Museum 2003.

32. Peña C, Wahlberg N, Weingartner E, Kodandaramaiah U, Nylin S, Freitas AVL, Brower AVZ: Higher level phylogeny of Satyrinae butterflies (Lepidoptera: Nymphalidae) based on DNA sequence data. Molecular Phylogenetics and Evolution 2006, 40:29-49.

33. Peña $C$, Wahlberg N: Prehistorical climate change increased diversification of a group of butterflies. Biology Letters 2008, 4:274-278.

34. Evans $W H$ : The Identification of Indian Butterflies. Mumbai, India: Bombay Natural History Society, 21932.

35. Ackery PR: Hostplants and classification: a review of nymphalid butterflies. Biological Journal of the Linnean Society 1988, 33:95-203.

36. Braby MF: The distribution, status and habitat associations of the Satyrinae (Lepidoptera: Nymphalidae) fauna of northeastern Australia. Journal of the Australian Entolomogical Society 1995, 34:51-61.

37. Wynter-Blyth MA: Butterflies of the Indian Region. Bombay:: Bombay Natural History Society 1957.

38. Lees DC: The Périnet Effect? Diversity gradients in an adaptive radiation of Madagascan butterflies (Satyrinae: Mycalesina) contrasted with other species-rich rainforest taxa. Biogeography of Madagascar Paris: ORSTOM ÉditionsLourenço WR 1996, 479-490.

39. Linares MC, Soto-Calderón ID, Lees DC, Anthony NM: High mitochondrial diversity in geographically widespread butterflies of Madagascar: A test of the DNA barcoding approach. Molecular Phylogenetics and Evolution 2009, 50(3):485-495.

40. Kremen C: Assessing the indicator properties of species assemblages for natural areas monitoring. Ecological Applications 1992, 2(2):203-217.

41. Kremen C: Biological inventory using target taxa: $A$ case study of the butterflies of Madagascar. Ecological Applications 1994, 4(3):407-422.

42. Brakefield PM, Larsen TB: The evolutionary significance of dry and wet season forms in some tropical butterflies. Biological Journal of the Linnean Society 1984, 22:1-12
43. Braby MF: Life history strategies and habitat templets of tropical butterflies in north-eastern Australia. Evolutionary Ecology 2002, 16(4):399-413

44. Kirk WD: Variation of forewing spot number in the mineus-group of Mycalesis (Lepidoptera, Satyridae) in S.E. Asia. Malayan Nature Journal 1982, 35:229-223.

45. Holloway GJ, Brakefield PM, Kofman S: The genetics of wing pattern elements in the polyphenic butterfly, Bicyclus anynana. Heredity 1993, 70:179-186.

46. Windig JJ: Genetic correlations and reaction norms in wing pattern of the tropical butterfly Bicyclus anynana. Heredity 1994, 73:459-470.

47. Robertson KA, Monteiro A: Female Bicyclus anynana butterflies choose males on the basis of their dorsal UV-reflective eyespot pupils. Proceedings of the Royal Society of London Series B Biological Sciences 2005, 272:1541-1546.

48. Breuker CJ, Brakefield PM: Female choice depends on size but not symmetry of dorsal eyespots in the butterfly Bicyclus anynana. Proceedings of the Royal Society B: Biological Sciences 2002, 269(1497):1233-1239.

49. Costanzo K, Monteiro A: The use of chemical and visual cues in female choice in the butterfly Bicyclus anynana. Proceedings of the Royal Society B: Biological Sciences 2007, 274:845-851.

50. Oliver JC, Robertson KA, Monteir0 A: Accomodating natural and sexual selection in butterfly wing pattern evolution. Proceedings of the Royal Society B: Biological Sciences 2009.

51. Brakefield PM, Gates J, Keys D, Kesbeke F, Wijngaarden PJ, Monteiro A, French V, Carroll SB: Development, plasticity and evolution of butterfly eyespot patterns. Nature 1996, 384:236-242.

52. Monteiro A, Prijs J, Bax M, Hakkaart T, Brakefield PM: Mutants highlight the modular control of butterfly eyespot patterns. Evolution and Development 2003, 5(2):180-187.

53. Beldade $P$, Rudd S, Gruber JD, Long AD: A wing expressed sequence tag resource for Bicyclus anynana butterflies, an evo-devo model. BMC Genomics 2006, 7:130.

54. Allen CE: The "Eyespot Module" and Eyespots as Modules: Development, Evolution, and Integration of a Complex Phenotype. Journal of Experimental Zoology (Mol Dev Evol) 2007, 310(2):179-190.

55. Arbesman S, Enthoven L, Monteiro A: Ancient Wings: animating the evolution of butterfly wings patterns. BioSystems 2003, 71(3):289-295

56. Whitfield JB, Kjer KM: Ancient Rapid Radiations of Insects: Challenges for Phylogenetic Analysis. Annual Review of Entomology 2008, 53:449-472.

57. Shavit L, Penny D, Hendy MD, Holland BR: The Problem of Rooting Rapid Radiations. Molecular Biology Evolution 2007, 24(11):2400-2411.

58. Kodandaramaiah U, Peña C, Braby MF, Grund R, Müller CJ, Nylin S, Wahlberg N: Phylogenetics of Coenonymphina (Nymphalidae: Satyrinae) and the problem of rooting rapid radiations. Molecular Phylogenetics and Evolution 2009, 54:386-394.

59. Peña C, Nylin S, Wahlberg N: The radiation of Satyrini butterflies (Nymphalidae: Satyrinae): a challenge for phylogenetic methods. Zoological Journal of the Linnean Society 2009, 39:243-258.

60. Hackett SJ, Kimbal RT, Reddy S, Bowie RCK, Braun EL, Braun MJ, Chojnowski JL, Cox WA, Han KL, Harshman J, et al: A Phylogenomic Study of Birds Reveals Their Evolutionary History. Science 2008, 320(5884):1763-1768.

61. Wiens JJ, Kuczynski CA, Smith SA, Mulcahy D, Sites JW Jr, Townsend TM, Reeder TW: Branch length, support, and congruence: testing the phylogenomic approach with 20 nuclear loci in snakes. Systematic Biology 2008, 57(3):420-431.

62. Hallström BM, Janke A: Resolution among major placental mammal interordinal relationships with genome data imply that speciation influenced their earliest radiations. BMC Evolutionary Biology 2008, 8(162)

63. Wahlberg N, Braby MF, Brower AVZ, de Jong R, Lee MM, Nylin S, Pierce N, Sperling FA, Vila R, Warren AD, et al: Synergistic effects of combining morphological and molecular data in resolving the phylogeny of butterflies and skippers. Proceedings of the Royal Society of London $B$ Biological Sciences 2005, 272:1577-1586.

64. Wahlberg N, Leneveu J, Kodandaramaiah U, Peña C, Nylin S, Freitas AVL Brower AVZ: Nymphalid butterflies diversify following near demise at the Cretaceous/Tertiary boundary. Proceedings of the Royal Society B: Biological Sciences 2009, 276:4295-4302. 
65. Kodandaramaiah $U$, Wahlberg N: Out-of-Africa origin and dispersal mediated diversification of the butterfly genus Junonia (Nymphalidae: Nymphalinae). Journal of Evolutionary Biology 2007, 20(6):2181-2191.

66. Flynn $L$, Jacobs LL: Late Miocene small mammal faunal dynamics: The crossroads of the Arabian peninsula. Fossil Vertebrates of Arabia New Haven: Yale University PressWhybrow PJ, Hill A 1999, 412-419.

67. Lecompte E, Aplin K, Denys C, Catzeflis François F, Chades M, Chevret P: Phylogeny and biogeography of African Murinae based on mitochondrial and nuclear gene sequences, with a new tribal classification of the subfamily. BMC Evolutionary Biology 2008, 8:199.

68. Lieberman BS: Unifying theory and methodology in biogeography. Evolutionary Biology 2003, 33:1-25.

69. Kodandaramaiah U: Eyespot evolution: phylogenetic insights from Junonia and related butterfly genera (Nymphalidae: Junoniini). Evolution and Development 2009, 11:489-497.

70. D'Abrera BL: Butterflies of the Afrotropical Region, Part I. Papilionidae, Pieridae, Nymphalidae, Satyridae. Melbourne: Hill House, 31997.

71. Phelan PL, Baker TC: Evolution of Male Pheromones in Moths: Reproductive Isolation Through Sexual Selection? Science 1987, 235(4785):205-207.

72. Nieberding C, Schneider M, de Vos H, Lassance J, Estramil N, Andersson J, Bång J, Hedenström E, Löfstedt C, Brakefield PMspitbBataeaPOe: Male sex pheromones in the butterfly Bicyclus anynana: towards an evolutionary analysis. Plos One 2008, 3(7):e2751.

73. Kodandaramaiah U: Vagility: The neglected component in historical biogeography. Evolutionary Biology 2009, 36(3):327-335.

74. Karanth KP: Evolution of disjunct distributions among wet-zone species of the Indian subcontinent: Testing various hypotheses using a phylogenetic approach. Current Science 2005, 85(9):101-108.

75. Janz N, Nylin S, Wahlberg N: Diversity begets diversity: host expansions and the diversification of plant-feeding insects. BMC Evolutionary Biology 2006, 6:4.

76. Nylin S, Wahlberg N: Does plasticity drive speciation? Host plant shifts and diversification in nymphaline butterflies (Lepidoptera: Nymphlidae) during the tertiary. Biological Journal of the Linnean Society 2007, 94:115-130.

77. Moore GJ: Host plant discrimination in tropical satyrine butterflies. Oecologia 1986, 70(4):592-595.

78. Kodandaramaiah U, Wahlberg N: Phylogeny and biogeography of Coenonympha butterflies (Nymphalidae: Satyrinae) - patterns of colonization in the Holarctic. Systematic Entomology 2009, 34:315-323.

79. Wahlberg N, Oliveira R, Scott JA: Phylogenetic relationships of Phyciodes butterfly species (Lepidoptera: Nymphalidae): complex mtDNA variation and species delimitations. Systematic Entomology 2003, 28:257-273.

80. Weingartner E, Wahlberg N, Nylin S: Speciation in Pararge (Satyrinae: Nymphalidae) butterflies - North Africa is the source of ancestral populations of all Pararge species. Systematic Entomology 2006, 31:621-632.

81. Leneveu J, Chichvarkhin A, Wahlberg N: Varying rates of diversification in the genus Melitaea (Lepidoptera: Nymphalidae) during the past 20 million years. Biological Journal of the Linnean Society 2009, 97(2):346-361.

82. Wahlberg N, Wheat CW: Genomic outposts serve the phylogenomic pioneers: designing novel nuclear markers for genomic DNA extractions of Lepidoptera. Systematic Biology 2008, 57:231-242.

83. Hall TA: BioEdit: a user-friendly biological sequence alignment editor and analysis program for Windows 95/98/NT. Nucleic Acids Symposium Series 1999, 41:95-98.

84. Goloboff PA, Farris JS, Nixon K: TNT, a free program for phylogenetic analysis. Cladistics 2008, 24(5):774-786.

85. Stamatakis A, Hoover P, Rougemont J: A Fast Bootstrapping Algorithm for the RAxML Web-Servers. Systematic Biology 2008, 57(5):758-771.

86. Posada D: jModelTest: Phylogenetic Model Averaging. Molecular Biology and Evolution 2008, 25(7):1253-1256.

87. Shimodaira H, Hasegawa M: Multiple comparison of log-likelihoods with applications to phylogenetic inference. Molecular Biology and Evolution 1999, 16(8):1114-1116.

88. Maddison WP, Maddison DR, MacClade 4: Analysis of Phylogeny and Character Evolution, Version 4. Sinauer Associates, Sunderland, MA 2004.

89. Swofford D: PAUP*- Phylogenetic Analysis Using Parsimony and Other Methods, Version 4. Sinauer Associates Sunderland, MA 2001.
90. Drummond AJ, Rambaut A: BEAST: Bayesian evolutionary analysis by sampling trees. BMC Evolutionary Biology 2007, 7(214).

91. Drummond AJ, Ho SYW, Phillips MJ, Rambaut A: Relaxed phylogenetics and dating with confidence. Plos Biology 2006, 4(5):699-710.

doi:10.1186/1471-2148-10-172

Cite this article as: Kodandaramaiah et al:: Phylogenetics and biogeography of a spectacular Old World radiation of butterflies: the subtribe Mycalesina (Lepidoptera: Nymphalidae: Satyrini). BMC Evolutionary Biology 2010 10:172.

\section{Submit your next manuscript to BioMed Central and take full advantage of:}

- Convenient online submission

- Thorough peer review

- No space constraints or color figure charges

- Immediate publication on acceptance

- Inclusion in PubMed, CAS, Scopus and Google Scholar

- Research which is freely available for redistribution

Submit your manuscript at www.biomedcentral.com/submit
Biomed Central 